\title{
A COMPARATIVE ANALYSIS OF IMAGE COMPRESSION USING PCM AND DPCM
}

\section{Gbaranwi Barima Precious ${ }^{1}$ and Kabari Ledisi Giok ${ }^{2}$}

${ }^{1}$ Department of Computer Science, Ignatius Ajuru University of Education, Rivers State, Nigeria. Email: gbaranwiprecious@yahoo.com

${ }^{2}$ Department of Computer Science, Ken Saro-Wiwa Polytechnic, Bori, Rivers State, Nigeria. Email: ledisigiokkabari@yahoo.com

Cite this article:

Gbaranwi B.P., Kabari L.G. (2021), A Comparative Analysis of Image Compression using PCM and DPCM. British Journal of Computer, Networking and Information Technology 4(1), 60-67. DOI:

10.52589/BJCNIT-

KYUR6RDW.

\section{Manuscript History}

Received: 8 June 2021

Accepted: 3 July 2021

Published: 20 July 2021

Copyright $(92020$ The Author(s). This is an Open Access article distributed under the terms of Creative Commons AttributionNonCommercial-NoDerivatives 4.0 International (CC BY-NC-ND 4.0 ), which permits anyone to share, use, reproduce and redistribute in any medium, provided the original author and source are credited.
ABSTRACT: The quality of the signal is essential in digital communication and signal processing. The transmission channel is also important. Modulation is used for effective transmission of signal. There exist several types of modulation techniques. One of such is the pulse code modulation (PCM). The performance of PCM is however affected by quantization error and noise in the transmission channel, which affects the quality of the output. Against this backdrop, this paper presents the use of differential pulse code modulation (DPCM) so as to address the limitation of pulse code modulation. The simulation environment is MATLAB 2018a. The MATLAB Simulink is used to design the PCM and DPCM systems using appropriate digital processing blocks. The DPCM system shows a significant improvement in terms of error reduction and quality of output.

KEYWORDS: Digital Signal Processing, Image Compression, PCM, DPCM, SNR, Simulink, MATLAB. 


\section{INTRODUCTION}

There are various ways of transmitting signal in recent years. However, the signal or message to be transmitted should be in the form that can be easily transmitted. Although there exists a considerable aspect of communication in analog form, it is being rapidly replaced by digital communication. In digital signal processing, it is essential for the message to be converted into digital form, which can be easily be processed and transmitted. One of the techniques for converting an analogue signal to digital form is the pulse code modulation (PCM). The PCM method consists of three stages, which include sampling, quantization and encoding.

The first essential step in a digital communication or signal processing system is the transformation of the source information into a form that is compatible with the digital system. The initial operation is referred to as sampling. Through the sampling process, an analog signal is converted into the corresponding sequence of samples. These samples are usually spaced in a uniform manner. During sampling, the signal is transformed into a discrete time signal. When the sampling process is completed, quantization begins. Quantization is another important stage in the PCM system where the output of the sampling is quantized to provide a new representation that is discrete in both time and amplitude. Quantization is also used for compression. The images are measured in pixels; 8-bits represent each pixel. An image is quantized in order to reduce the bandwidth required for its transmission. Thus, the image is quantized into smaller numbers of bits per pixel. Thereafter, the encoder encodes the quantized image. Each quantized signal is encoded into bits, a stream of bits in binary form. Nevertheless, for quantized signal in image compression, the quantized signal is encoded into 8-bits precisely where 8-bits represents each pixel. This is done before being transmitted over the channel.

The performance of PCM is however affected by quantization error and noise in the transmission channel, which affects the quality of the output. To have an improved quality, differential pulse code modulation (DPCM) is introduced to address the limitation of pulse code modulation. Here, several factors are considered so as to achieve greater compression rates without significant loss of image quality.

In the digital communication and signal processing, the quality of the message or signal is essential. The transmission channel is also important. The process involved in transmitting data or signal is referred to as modulation. There exist several types of modulation techniques. One of such is the pulse code modulation (PCM). It is a technique used in converting analog signal into digital form. The performance of PCM is however affected by quantization error, distortion, among other factors, which affects the quality of the output. Hence, the need to employ the use of differential pulse code modulation (DPCM) techniques to achieve improved quality.

This paper presents a comparative analysis of image compression using PCM and DPCM. We design a model for PCM and DPCM, then implement the model using MATLAB Simulink and evaluate them in terms of performance and quality of output. 


\section{RELATED WORK}

There are different techniques for modulation. Modulation can be categorized as continuous wave modulation or pulse code modulation (PCM). Pulse code modulation falls into the category of digital modulation (Shetty et al., 2015).

The process of modulating a message for transmission is made practicable through the use of digital communication techniques (Achkar et al., 2012). Haidar et al. (2019) noted that differential pulse code modulation uses the baseline of PCM, but adds some functionality based on the prediction of the future values of the signal.

In DPCM, quantization error is reduced due to the use of a prediction filter. The signal to noise ratio (SNR) is also improved, thus allowing better noise filtering with less bandwidth (Haidar et al., 2016). In a communication system, the difference between the adjacent time samples for images is small. Compressing an image is however different from compressing raw data (Tyagi \& Sharma, 2012).

\section{METHODOLOGY}

Digital signal processing is used for this study. The pulse code modulation (PCM) and differential pulse code modulation (DPCM) systems are modelled using Simulink and the simulation environment is MATLAB 2018a. The Simulink implementation of both PCM and DPCM systems for audio are shown in Figures 1, 2 and 3. The graph showing the error rate of the PCM system is shown in Figure 4 whereas image modulation is shown in Figures 5 and 6 respectively.

Figure 1 shows the implementation of PCM. Figure 2 shows the PCM system with error rate when it is run. Figure 3 shows the graph of the error display which necessitates the introduction of DPCM that has additional digital signal processing blocks to filter and reduce errors. The implementation of DPCM is shown in Figure 4. Emphasis is however on Figure 5 and 6,showing the implementation of image compression using PCM and DPCM.

The appropriate digital signal processing blocks were used. Figure 5 shows the processes involved in the PCM system. The first block is the input image reader (image from file). The input image can either be read from the workspace or a file. Nevertheless, images from the file block are used for this study. It gives room for the user to browse and select the image from an external source - outside the MATLAB workspace. The parameter for the image is set including the data type. Thereafter, the parameter is set for the next block, which is the submatrix block to determine if the output is according to the range of rows and columns. The data type conversion block converts the input to the data and scaling of the output. Here, the real values of the input are expected to correspond with the output. However, overflows and quantization errors can prevent this from being completely achieved. Of course, the quantizer discretizes the input. The data type conversion block 2 ensures that the input and output have equal real world value (RWV). The uniform encoder encodes the input into a specified number of bits. The output data type is set to 8-bits because 8-bits is used to represent one pixel for images. The received signal is then decoded by the decoder. Low pass filter sets the parameters for the frequency, pass-band and stop-band. The DPCM system in 
British Journal of Computer, Networking and Information Technology

ISSN: 2689-5315

Volume 4, Issue 1, 2021 (pp. 60-67)

www.abjournals.org

Figure 6 follows a similar routine but more blocks are added to handle complex algebraic processes and error reduction.

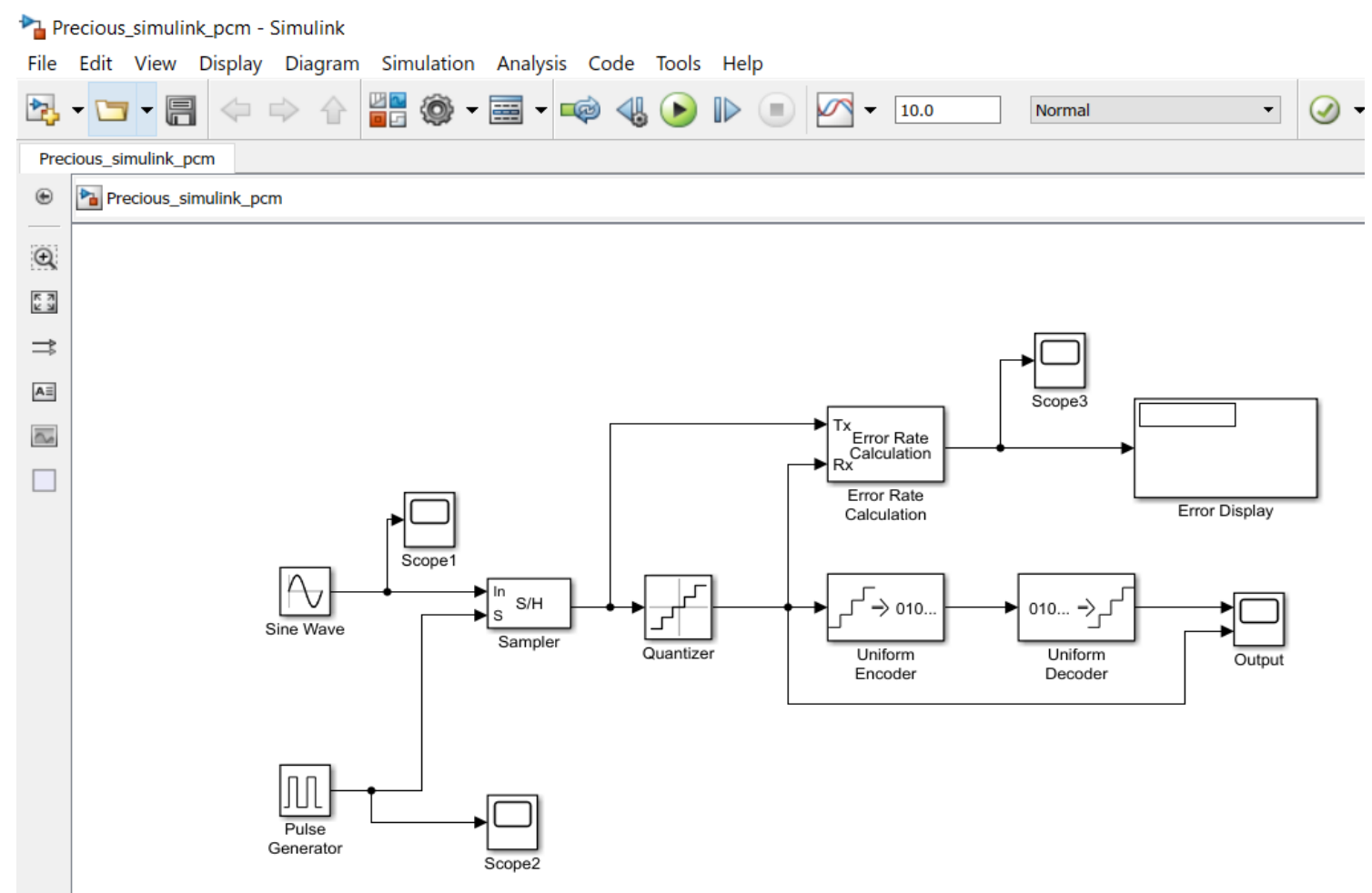

Figure 1: MATLAB Simulink Implementation of PCM

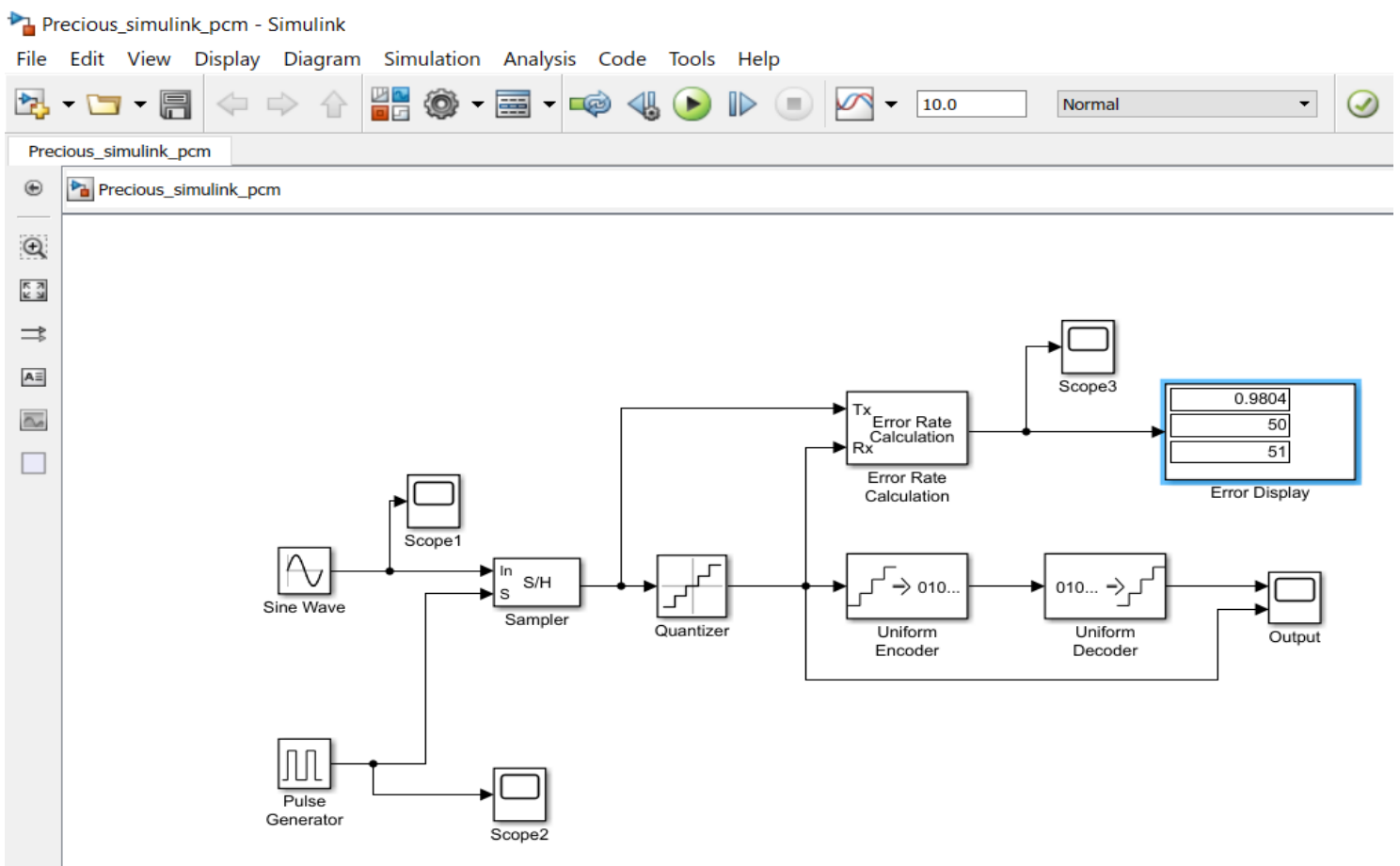

Figure 2: MATLAB Simulink Implementation of PCM with Error Display 
British Journal of Computer, Networking and Information Technology

ISSN: 2689-5315

Volume 4, Issue 1, 2021 (pp. 60-67)

www.abjournals.org

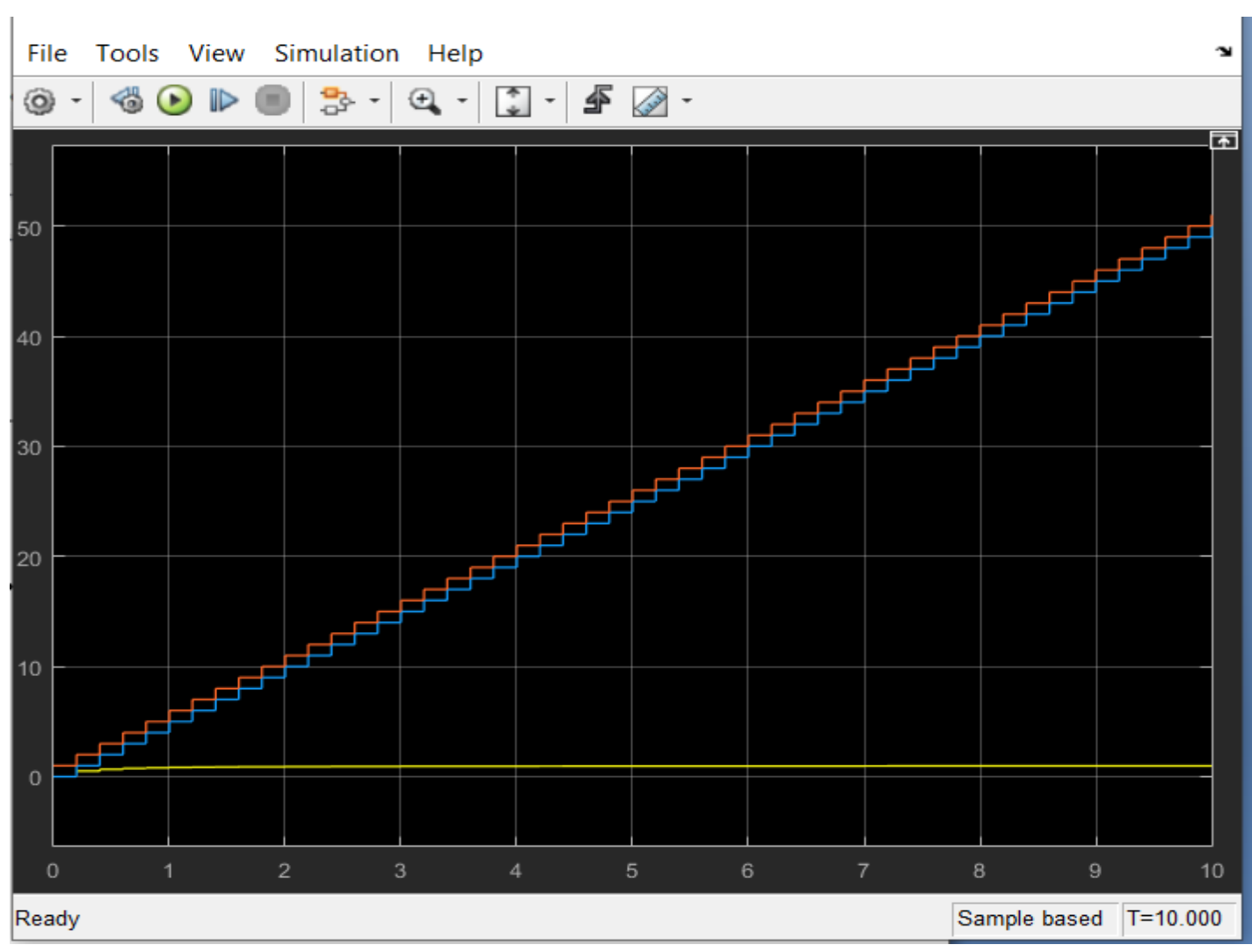

Figure 3: Graph Showing the Error Display

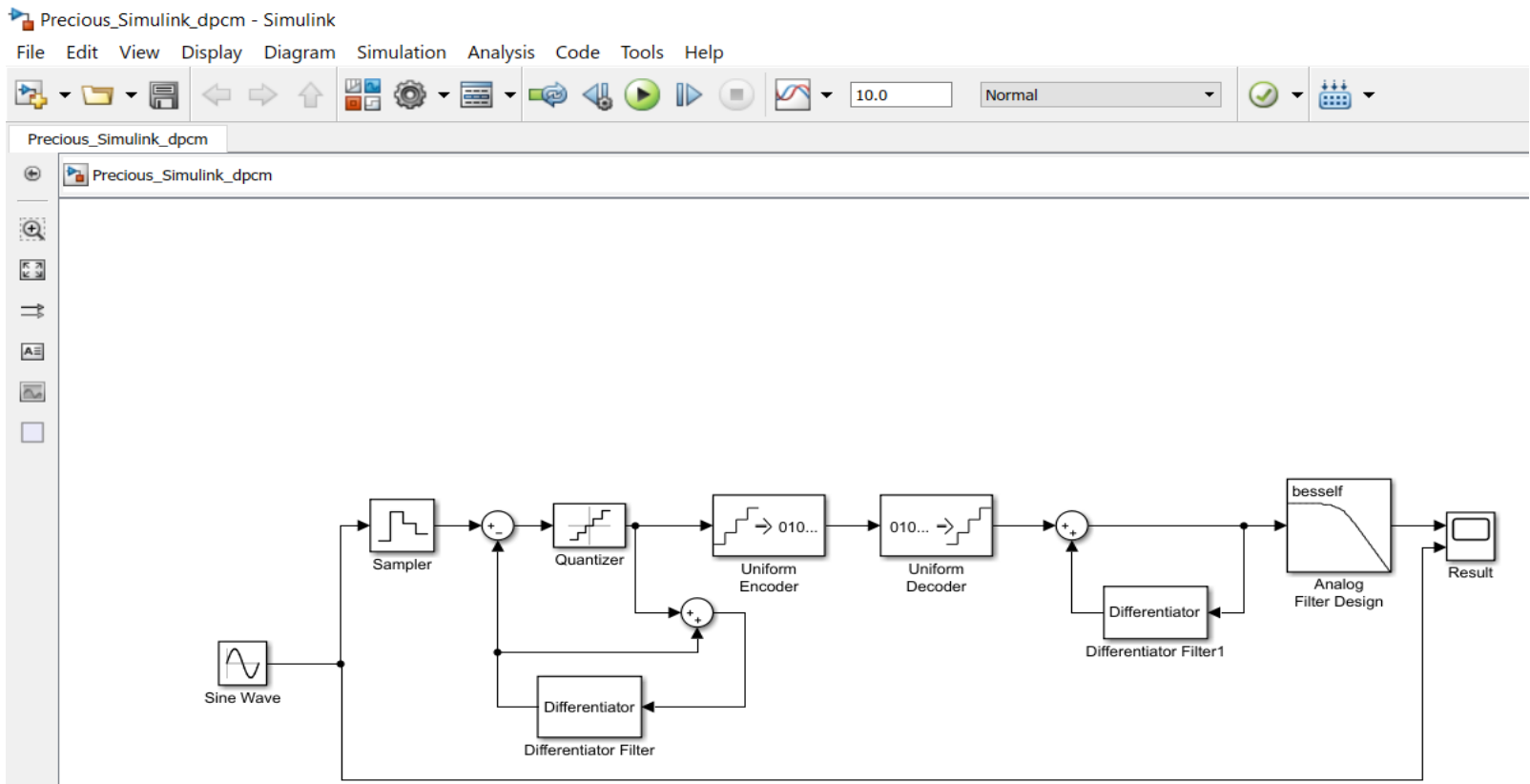

Figure 4: MATLAB Simulink Implementation of DPCM 
British Journal of Computer, Networking and Information Technology

ISSN: 2689-5315

Volume 4, Issue 1, 2021 (pp. 60-67)

www.abjournals.org

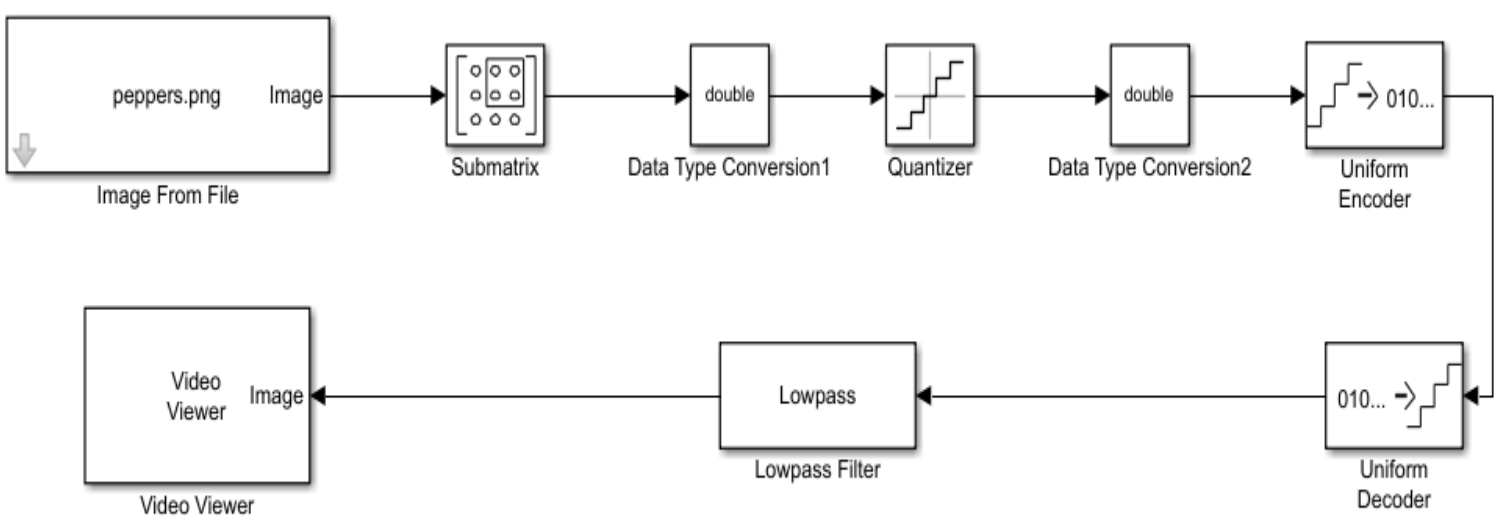

Figure 5: Simulink Implementation of Image Compression for PCM

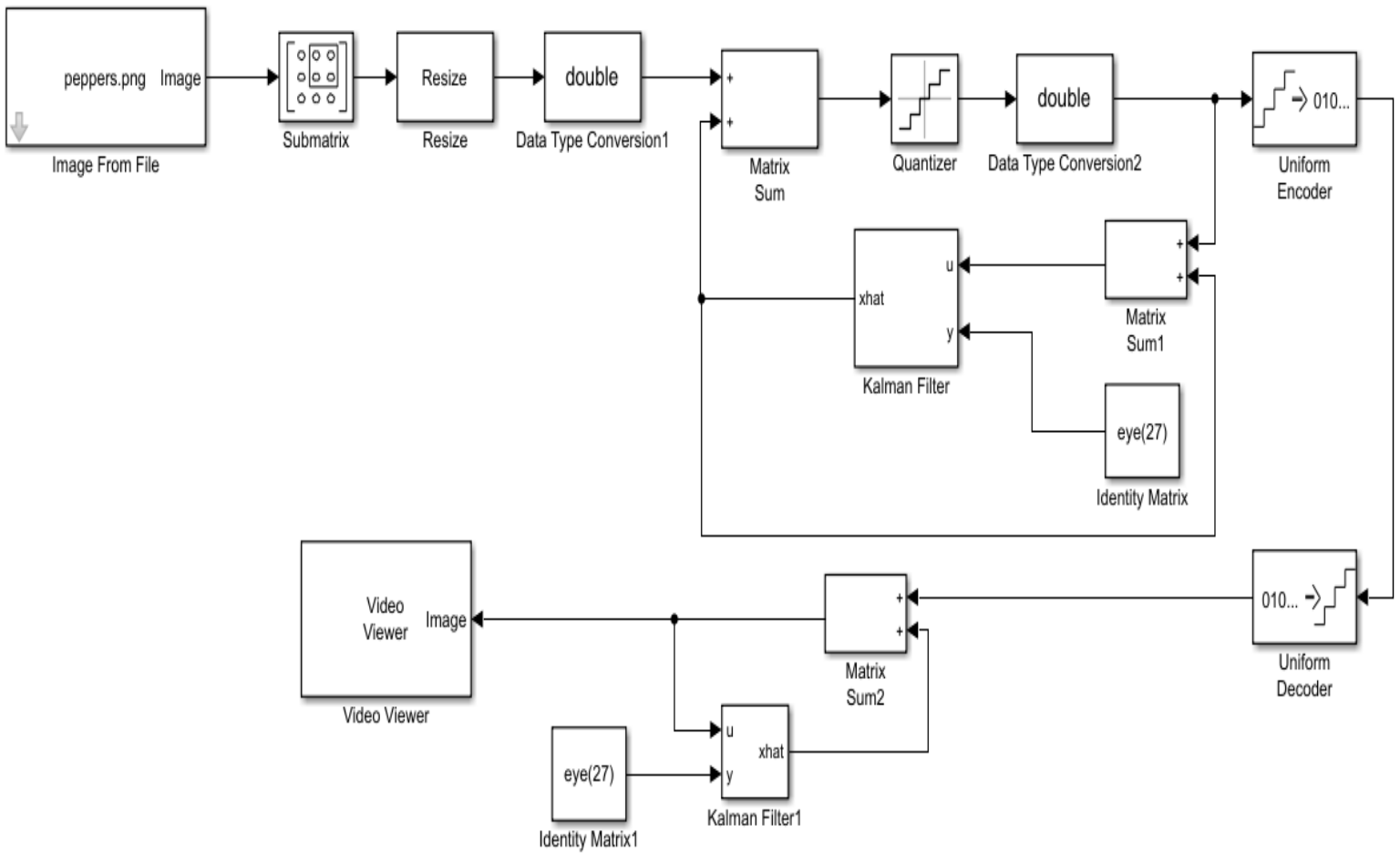

Figure 6: Simulink Implementation of Image Compression for DPCM 


\section{RESULTS AND DISCUSSION}

The implementation of PCM and DPCM systems differ in terms of the output as shown in Figure 1, 2, 3, 4, 5 and 6. Figure 1 to 4 shows the implementation of PCM and DPCM for audio modulation. Emphasis is however on Figures 5 and 6 which show the implementation of image compression using PCM and DPCM. There is a significant difference between the PCM and DPCM system for image modulation or compression. PCM is affected by quantization error, distortion, among other factors. As shown in Figure 6, the DPCM system follows a similar routine but more blocks are added to handle the complex algebraic processes, so as to achieve the desired result. Filters are also introduced to get improved quality output. Compared to PCM, DPCM performs better in terms of error reduction and quality of output.

Table 1: Comparison of PCM and DPCM

\begin{tabular}{|l|l|l|}
\hline Parameters & $\begin{array}{l}\text { Pulse Code Modulation } \\
\text { (PCM) }\end{array}$ & $\begin{array}{l}\text { Differential Pulse Code Modulation } \\
\text { (DPCM) }\end{array}$ \\
\hline Bandwidth & It requires high bandwidth. & $\begin{array}{l}\text { Low bandwidth required compared } \\
\text { to PCM. }\end{array}$ \\
\hline Quantization Error & It contains quantization error. & Quantization error is reduced. \\
\hline Simplicity & It is simple. & $\begin{array}{l}\text { It is not simple; it requires the use of } \\
\text { a predicator circuit which is } \\
\text { complex. }\end{array}$ \\
\hline Quality of output & $\begin{array}{l}\text { Poor quality due to the effect } \\
\text { of distortion. }\end{array}$ & Improved quality. \\
\hline
\end{tabular}

\section{CONCLUSION}

This study provides a fascinating discussion on pulse code modulation (PCM) and differential pulse code modulation (DPCM). It also explores image compression using PCM and DPCM. The performance of PCM is affected by its limitations, which include data redundancy, quantization error and distortion. As a result, the quality of the transmitted signal is affected. Thus, DPCM is introduced to achieve reduced quantization error and improved quality. The PCM and DPCM systems are designed and implemented using MATLAB Simulink. 


\section{REFERENCES}

Achkar, R., Haidar, G. A., \& Mansour, C. (2012). Real-time application of DPCM and ADM systems. IEEE, IET International Symposium on Communication Systems, Networks and Digital Signal Processing.https://www.researchgate.net/publication/246044686

Haidar, G. A., Achkar, R., \& Dourgham, H. (2016). A comparative simulation study of the real effect of PCM, DM and DPCM systems on audio and image modulation. https://doi.org/10.1109/IMCET.2016.77774442

Haidar, G. A., Achkar, R., \& Dourgham, H. (2019). Quality verification of audio and image modulation by the simulation of PCM, DM and DPCM systems. International Journal of Information and Communication Sciences, 10(10), 1 - 12.

Shetty, S., Varghese, S., \& Wagh, K. (2015). Design and implementation of pulse code modulation using MATLAB Simulink. International Journal of Advanced Research in Electronics and Communication Engineering, 4(11), 2814 - 2817.

Tyagi, R., \& Sharma, D. K. (2012). Digital image compression comparisons using DPCM and DPCM with LMS algorithm. International Journal of Computer Applications \& Information Technology, 1(11), 65 - 71. 